\title{
A ATUAÇÃO DO BIBLIOTECÁRIO NA MEDIAÇÃO IMPLÍCITA DA INFORMAÇÃO EM BIBLIOTECAS UNIVERSITÁRIAS
}

\author{
THE LIBRARIAN LABOR IN THE IMPLICIT MEDIATION OF INFORMATION IN \\ UNIVERSITY LIBRARIES
}

\section{F. P. SANTOS ${ }^{1, *}$, L. V. RENAULT ${ }^{2}$}

1 Universidade Federal de Minas Gerais, Programa de Pós-Graduação em Ciência da Informação Escola de Ciência da Informação, Brasil

2 Universidade Federal de Minas Gerais, Programa de Pós-Graduação em Ciência da Informação Escola de Ciência da Informação, Brasil., Brasil

\author{
ART ICLE INFO \\ Article history: \\ Received 2018-07-02 \\ Accepted 2018-08-17 \\ Available online 2018-08-31 \\ ${ }^{*}$ Autor correspondente: \\ E-mail: fabiana.ufmg@gmail.com
}

Palavras-chave: Profissional bibliotecário. Mediação implícita. Mediação. Bibliotecas Universitárias.

Keywords: Libranship. Implicit mediation. Mediation. University Libraries.

RESUMO. Este trabalho discute a mediação implícita no contexto do trabalho bibliotecário. Em um primeiro momento se discute os aspectos introdutórios do conceito de mediação e sua categorização em explícita e implícita. Logo em seguida se aprofunda na conceituação de mediação implícita e sua configuração no mundo do trabalho bibliotecário. Na seqüência, faz-se uma discussão sobre as funções exercidas pelos bibliotecários e suas implicações para a mediação implícita no contexto das bibliotecas universitárias. O argumento utilizado é da necessidade de conscientização do bibliotecário da relevância de sua ação mediadora implícita. Dessa forma, se demonstra a importância das atividades de desenvolvimento de coleções, processamento técnico e preservação como atividades de mediação implícita, complementares às de circulação e referência como atividades explícitas. Neste sentido, a conscientização visa tornar o profissional bibliotecário protagonista de suas aç̃es e com a dimensão do impacto social que podem gerar. Dessa forma, se problematiza a suposta neutralidade em que se ancora, por exemplo, a atividade de processamento técnico, visto que, a indexação traz consigo uma subjetividade inerente que, ao invés de ser combatida, deve ser compreendida e por vezes enfrentada.

ABSTRACT. This work discusses the mediation implicit in the context of the labor of librarians. In a first moment if discusses the introductory aspects of the concept of mediation and their categorization in explicit and implicit. Then deepens in the conceptualization of the implicit mediation and its configuration in the world of librarian labor. In the sequence, it is a discussion about the functions performed by librarians and their implications for the mediation implicit in the context of university libraries. The argument used is the need for awareness of the librarian for the relevance of their mediator action implied. That way, if demonstrates the importance of the activities of collection development, cataloguing and preservation as mediation activities implied, that, in the turn, are complementaries to the explicit reference activities. In this sense, the awareness aims to become the professional librarian protagonist of their actions and with the size of the social impact that can generate. That way, if discusses the supposed neutrality in that found, for example, in the activity of cataloguing, since the indexing brings a subjectivity inherent in that, instead of being combated, must be understood and sometimes faced. 


\section{Introdução}

A universidade tem como uma de suas responsabilidades a produção e desenvolvimento de conhecimentos que podem ser utilizados por toda a sociedade e, para isso, ela deve oferecer um ambiente propício. É importante dele se apropriar para a construção de práticas que auxiliem e incentivem os estudantes a serem sujeitos criativos, autônomos e críticos no desenvolvimento de habilidades de construção de conhecimento.

O atual contexto da Universidade tem se caracterizado por mudanças tecnológicas, culturais e científicas muito rápidas, o que exige capacitações e habilidades de formação continuada, bibliotecários sintonizados com a dinâmica da informação e capazes de agirem como mediadores no acesso às suas fontes, bem como prontos para atuarem também como educadores (SANTOS, 2015, p. 18).

Em uma biblioteca universitária, os trabalhos podem ser divididos em catalogação, preservação e conservação, circulação e referência. O setor de catalogação será responsável por inserir os itens na base de dados e entregá-los prontos para guarda na estante ou referenciá-los para acesso remoto, no caso dos livros e artigos de revistas eletrônicas por exemplo. O setor de preservação e conservação deverá cuidar da integridade dos livros, por meio de consertos e reparos, para que eles possam ter maior vida útil. O setor de circulação e referência será responsável pela gestão dos empréstimos e devoluções, bem como orientação e capacitação dos usuários para utilização da Unidade de Informação e dos serviços e produtos oferecidos por essa.

Vale ressaltar que nem todos os profissionais exercem todas as funções citadas acima, definições que dependem de sua posição dentro da Unidade de Informação, de seu perfil e do objetivo do órgão em que cada um atua. Porém neste trabalho acreditamos que em todas estas funções o profissional bibliotecário faz ações de mediação da informação. O objetivo desse ensaio é pensar as atividades de mediação implícitas realizadas por bibliotecários que atuam em bibliotecas universitárias.

Este trabalho partiu de um levantamento de literatura, identificando materiais que contribuíssem para construção do mesmo. Ele está dividido em quatro seções, esta primeira introdução; a próxima seção em que abordaremos a mediação da informação em suas duas formas: implícita e explícita; a terceira seção em que falaremos sobre o fazer e as ações dos bibliotecários na mediação implícita da informação; e a última seção que consiste das considerações finais.

\section{Mediação da informação}

Para se entender o conceito de Mediação da Informação ao qual queremos evocar neste trabalho é fundamental entender e refletir sobre que Informação estamos pensando em mediar, e quais são as premissas básicas que esta definição traz para o nosso contexto. 
Almeida Júnior afirma

A mediação da informação permite exige a concepção de informação que desloque o usuário da categoria de mero receptor, colocando-o como ator central do processo de apropriação. Dessa forma, defendemos que o usuário é quem determina a existência ou não da informação. A informação existe apenas no intervalo entre o contato da pessoa com o suporte e a apropriação da informação. Como premissa, entendemos a informação a partir da modificação, da mudança, da reorganização, da reestruturação, enfim, da transformação do conhecimento. (ALMEIDA JÚNIOR, 2009, p. 97)

Capurro (2003), Capurro e Hjorland (2007) ao tentarem trazer um conceito científico de informação encontram três vias possíveis para o compreender: informação física, em sentido cognitivo ou como um fenômeno social. Aqui acreditamos que o ultimo nos representa, pois a informação é aqui percebida como transformadora, inquietante, contextualizada, propulsora de mudança social e também modificada pelo meio. Ao falar das reflexões de Capurro sobre a informação como fenômeno social, Araújo acredita que

Antes, o modelo de informação "social" entende que informação é uma construção (algo é informativo num momento, em outro já não é mais; tem relevância para um grupo, mas não para outro; e assim sucessivamente). E mais, é uma construção conjunta, coletiva - ou melhor, intersubjetiva. O que é informação não é produto de uma mente única, isolada, mas construído pela intervenção dos vários sujeitos e pelo campo de interações resultante de suas diversas práticas. (ARAÚJO, 2010, p. 97)

Almeida Júnior ainda afirma que

[...] a informação é efêmera e se concretiza apenas no momento em que se dá a relação do usuário com o suporte que torna possível a existência dela, informação. Assim, ela não existe a priori. Não existe antes da relação usuário/suporte, que redunda em defendermos que o profissional da informação trabalha com uma informação latente, um quase- informação. (ALMEIDA JÚNIOR, 2009, p. 98)

A mediação da informação sempre foi comumente vista e pensada no setor de referência de uma biblioteca, porém neste estudo partimos do pressuposto que as ações de mediação perpassam todo o fazer biblioteconômico. Ainda mais se pensarmos em contextos universitários, uma vez que é necessário engajamento e entrosamento entre os profissionais da biblioteca e instituição a qual ela faz parte para que se alcance a missão da universidade. Sanches e Rio corroboram esta ideia e acreditam que

Pensando de forma mais abrangente o trabalho do profissional da informação, em particular a biblioteca universitária, sua atuação deve apoiar as atividades de ensino, pesquisa e extensão dentro da universidade e, assim, comprometer-se com o desenvolvimento da sociedade, faz-se necessário no presente momento da história rever e reavaliar os conceitos e práticas até agora exercidas. O que se faz presente nos estudos referentes à linha de pesquisa Mediação da Informação. (SANCHES; RIO, 2010, p. 103)

Desse modo, já eliminamos um pensamento comum das áreas de Biblioteconomia e Ciência da Informação que trata a mediação como ponte. Tratada como algo estático, imóvel, imparcial e sem atividade. Na ideia de mediação da informação aqui utilizada não há, e nem 
poderá existir a tão sonhada neutralidade por parte do trabalho bibliotecário, nem por parte do usuário. Nesta concepção de mediação, o usuário é sujeito ativo, pensante. É modificado e modifica a relação e o contexto no qual atua.

O conceito de mediação da informação pode ser visto como uma contraproposta ao de disseminação da informação, pois o último traz a ideia da entrega de uma informação que atendesse uma determinada demanda, sem interferências. Grosso modo, neste pensamento, existe um emissor e um receptor, em que um não sofre influencias do outro. Talvez daí advenha o mito da neutralidade do trabalho bibliotecário.

Refletir sobre as ações de mediação é de grande importância para a consolidação de uma Ciência da Informação, Biblioteconomia e para a prática do profissional bibliotecário, porém este conceito ainda necessita de ser mais bem fundamentado e pesquisado. Silva afirma que

Todavia, embora a mediação seja um conceito trabalhado na Ciência da Informação, especialmente em fins do século XX e início do século XXI compreende-se que a mediação na Ciência da Informação ainda se configura como conceito embrionário e premente de uma construção de sentidos mais sólida. (SILVA, 2015, p. 94)

Assim, o conceito de mediação da informação, apesar de sua fluidez, e como já dito anteriormente, está presente em todas as atividades do bibliotecário, embora existam controvérsias sobre a consciência dessa atuação por parte destes profissionais, posto que, para Almeida Júnior

Mediação da Informação é toda a ação de interferência - realizada pelo profissional da informação -, direta ou indireta; consciente ou inconsciente; singular ou plural; individual ou coletiva; que propicia a apropriação de informação que satisfaça, plena ou parcialmente, uma necessidade informacional. [...] a mediação não estaria restrita apenas a atividades relacionadas diretamente ao público atendido, mas em todas as ações do profissional bibliotecário, em todo fazer desse profissional. (ALMEIDA JÚNIOR, 2008, p. 46)

O direcionamento em torno da questão profissional é uma forte tendência dentro dos estudos em Ciência da Informação, ou seja, neste sentido é a própria prática bibliotecária que vai municiar a construção teórica do conceito de mediação da informação. Dessa forma, para Sanches e Rio

Mediar é construir em conjunto espaços que ative no profissional bibliotecário, agora não mais um profissional passivo, uma postura comprometida com sua classe profissional e com a comunidade a qual atende culminando em um compromisso com a sociedade fazendo que seu ramo de atividade seja reconhecido socialmente por sua importância. (SANCHES; RIO, 2010, p. 110)

No entanto, dentro do espectro social, a que o termo está inserido, importante perceber a sua característica cultural e seus desdobramentos como potência de significado e encontro entre o objeto e o sujeito, pois para Ortega (2015, p. 76) 
A mediação da informação implica intervenção, ação propositiva, intencionalidade, cujo objetivo é a apropriação da informação. É realizada sobre base material, por meio de metodologias de rigor científico. Identificação, seleção, produção de registros, ordenação, preservação, exposição de todo e qualquer objeto são atividades documentárias no sentido de que constituem - de modo articulado entre si - ações de mediação a partir das quais se dá a transformação do objeto em documento. (ORTEGA, 2015, p. 76)

Ainda sobre a conformação cultural, importante notar a mediação sob as relações de conflito, tensionalidades e intencionalidades, visto que o sujeito é construtor de sua realidade com vistas a manutenção ou transformação da mesma. Neste sentido, Silva afirma que,

a mediação da informação é um construto que parte dos 'seres sociais' (relações múltiplas, plurais e coletivas entre os seres) e se consolida na formação da consciência do ser (passível de singularidade interpretativa de cada ser). De outro modo, a mediação é um construto social que se estabelece entre o ser e o mundo aproximando a teoria conhecimento) da prática (ação), sendo que a construção de conhecimento deve ser composta a partir do real ou concreto (das configurações sociais, materiais e históricas), com vistas a transformação da realidade do(s) ser(es). (SILVA, 2015, p. 102)

Almeida Júnior, após leituras, reflexões e avanços nas discussões em um grupo de estudo sobre esta temática, ainda se propõe reformular o conceito de mediação da informação, por acreditar ser necessário atender um novo entendimento. Assim, o divulga em um capítulo de livro publicado em 2015 que

Mediação da informação é toda ação de interferência - realizada em um processo, por um profissional da informação e na ambiência de equipamentos informacionais -, direta ou indireta; consciente ou inconsciente; singular ou plural; individual ou coletiva; visando a apropriação de informação que satisfaça, parcialmente e de maneira momentânea, uma necessidade informacional, gerando conflitos e novas necessidades informacionais. (ALMEIDA JÚNIOR, p.25, 2015)

Assim, a mediação da informação perpassaria todas as ações do bibliotecário em seu fazer diário dentro de uma biblioteca ou unidade de informação. Para Almeida Júnior

A mediação estaria presente, de maneira não explicitada, na seleção, na escolha dos materiais que farão parte do acervo da biblioteca, em todo o trabalho de processamento técnico, nas atividades de desenvolvimento de coleções e, também, no serviço de referência e informação. (ALMEIDA JÚNIOR, p.46, 2015)

É perceptível então, a necessidade de se fazer a distinção entre a mediação da informação implícita, presente na seleção, processamento técnico, desenvolvimento de coleções e preservação do acervo; da mediação explícita contida no Serviço de Referência e Informação. Almeida Júnior afirma que

A mediação explícita, por seu lado, ocorre nos espaços em que a presença do usuário é inevitável, é condição sine qua non para sua existência, mesmo que tal presença não seja física, concreta e presencial do profissional da informação. (ALMEIDA JÚNIOR, p.93, 2015) 
Vale ressaltar que o serviço de referência não era visto como apenas constituído de atendimento ao usuário, esta seria apenas uma das etapas do trabalho de um bibliotecário que atua no setor de referência de uma biblioteca. O atendimento ao usuário é a etapa final, pois para que ele aconteça é necessário que haja seleção, aquisição e organização dos materiais informacionais. De acordo com Hutchins

A seleção e organização de materiais com este fim em vista é uma parte tão importante do trabalho de referência quanto sua interpretação para o leitor individual. É a força motriz sem o qual o alvo não pode ser atingido. Para obter um serviço de referência eficiente a administração da biblioteca precisa supri-lo tanto com os necessários livros e instalações quanto com uma equipe treinada em seu manuseio. (HUTCHINS, 1973, p. 4)

Porém este mesmo movimento não era sentido com a mediação da informação. Assim, percebemos que a mediação não pode ser discutida somente do ponto de vista do atendimento ao usuário no Serviço de Informação e Referência, mas também sob o olhar da organização para o acesso. Esses pontos de vista estão dialeticamente imbricados, o mesmo valendo para o contrário. E é neste contexto que vem a tona o conceito de mediação implícita da informação. O que nada mais é que todas as atividades do fazer biblioteconômico com finalidade de dar suporte ao atendimento ao usuário, realizadas sem a presença do mesmo. Para que este atendimento ocorra de forma a dar acesso de maneira eficiente e eficaz. Para Almeida Júnior

A mediação implícita ocorre nos espaços dos equipamentos informacionais em que as ações são desenvolvidas sem a presença física e imediata dos usuários. Nesses espaços, como já observado, estão a seleção, 0 armazenamento e o processamento da informação. (ALMEIDA JÚNIOR, p.93, 2009)

Silva (2015) ao tentar identificar e explicitar alguns tipos de mediação passíveis de serem aplicados principalmente em Centros de Informação enuncia três tipos: mediação técnica da informação, mediação pedagógica da informação, e por fim, mediação institucional da informação. Neste trabalho, o que ele chama de mediação técnica da informação é o que mais nos interessa, pois concerne às ações de organização, representação da informação. Em uma biblioteca universitária a mediação implícita da informação está nas atividades de seleção, processamento técnico, catalogação e preservação, ou seja, nas ações de organização e representação da informação. São sobre estas ações que iremos refletir na próxima seção.

\section{O fazer do bibliotecário na mediação implícita da informação}

Acredita-se que as ações de interferência estão indissociadas do fazer do bibliotecário, porém não é assim que os profissionais tendem a perceber suas práticas. Santos Neto e Almeida Júnior ao analisar os discursos de bibliotecários que atuam em uma biblioteca 
universitária captam que ainda falta a consciência por parte do profissional de que as ações de mediação estão em todos os processos biblioteconômicos e afirmam que

\begin{abstract}
Os bibliotecários, em sua maioria, ainda não têm uma noção clara de que seu trabalho nos serviços meios são também trabalhos de mediação da informação. Também não têm claro que interferem o tempo inteiro em seus processos e práticas informacionais. Defende-se que as ações de interferência dos bibliotecários, não só asseguram um fazer ético, mas procuram também desempenhar sua função social nos processos informacionais que fundam a sociedade biblioteconômica e continuam a ser processados nos novos ambientes e contextos. (ALMEIDA JÚNIOR, 2017, p. 261)
\end{abstract}

O que se pretende aqui é mostrar como a intencionalidade nas ações de interferência no fazer do bibliotecário influencia e torna possível o processo de mediação implícita da informação. Para Almeida Júnior (2008, p. 48)

Retomando o conceito de mediação da informação, é mister que se reafirme a importância da interferência no fazer do profissional da informação. Mesmo buscando a imparcialidade - e sabendo que ela nunca será alcançada - 0 profissional deve se preocupar com a relação muito próxima entre interferência e manipulação. Esta, sim, deve ser totalmente abolida das ações do profissional, embora no trabalho cotidiano, mesmo que inconscientemente, todo o profissional está sujeito a se defrontar com ela em seu fazer. A linha que separa a interferência da manipulação é extremamente tênue. Apesar disso, o profissional da informação deve procurar o difícil equilíbrio sobre essa linha. (ALMEIDA JÚNIOR, 2008, p. 48)

Em uma biblioteca universitária o processo de mediação implícita se inicia na seleção dos materiais que irão compor o acervo. Vários são os fatores a serem levados em consideração na seleção: o assunto, a quantidade em números do item na coleção, o estado físico, o valor monetário e até mesmo o doador. Por exemplo: materiais de assuntos não correlatos à área de conhecimento que à biblioteca atende são separados e não entram para a coleção; livros doados por professores da entidade e que serão utilizados em suas aulas tem lugar garantido. Enfim, o processo de seleção é coberto por escolhas que vão depender de cada instituição e sua missão, assim o profissional deve estar atento a cumprir estas determinações, bem como empenhar sua experiência para tomar estas atitudes.

No processamento técnico, as interferências poderão ocorrer ao se dar preferência em se trabalhar com determinados materiais em função de outros. Como ao acreditar ser mais importante carimbar, colar fitas de segurança em teses e dissertações produzidas por alunos da instituição antes que em livros doados. Ao se decidir que após a catalogação é mais importante fazer primeiro as etiquetas dos livros comprados em relação aos doados. Além disso, fundamental lembrar que as políticas de indexação dos materiais têm papel fundamental na recuperação da informação por parte dos usuários. Neste sentido, o processamento técnico é quem produz a linguagem mediadora entre a coleção e o usuário. 
$\mathrm{Na}$ oficina de conservação de materiais a mediação da informação pode ser dar ao decidir se livros em péssimo estado físico irão ser consertados ou se irão ser descartados, pois o custo não vale a pena. Ou se materiais com determinados tipos de fungos podem ou não voltar a ser utilizado pelos usuários.

É perceptível, que as tomadas de decisões do bibliotecário interferem diretamente nos materiais e nas informações disponibilizadas, bem como traz consequências na vida dos usuários e rotina da Biblioteca. Assim, as ações de mediação implícita realizadas pelo profissional têm alto poder de transformação e mudança social.

E por isto a importância de não negar a interferência, pois uma vez reconhecida ela deverá ser autovigiada, tornada consciente e crítica, para que o bibliotecário possa lidar com ela de forma madura, com objetivo de eliminar ou diminuir a manipulação e consequentemente, prever seus riscos e consequências. De acordo com Almeida Júnior

O profissional da informação, a partir da consciência da interferência, passa a ser entendido em uma outra esfera, em um outro extrato profissional, o daqueles que fazem história, são sujeitos na sociedade e participam efetivamente da construção do destino da humanidade. (ALMEIDA JÚNIOR, 2008, p. 48)

De acordo com Almeida Júnior (2009, p. 93) "A mediação da informação é um processo histórico-social. O momento em que se concretiza não é um recorte de tempo estático e dissociado de seu entorno. Ao contrário: resulta da relação dos sujeitos com o mundo".

Enfim, muito ainda se tem a caminhar com relação ao entendimento da mediação da informação no âmbito do fazer biblioteconômico, uma delas é implantar e firmar disciplinas com esta temática nos cursos de graduação e pós-graduação da área. Acreditamos que este passo seria uma confirmação do papel central que tem a mediação não somente nas ações do Serviço de Referência e Informação, mas em todas as etapas do trabalho do profissional da informação. Almeida Júnior finaliza seu trabalho fortalecendo esta questão ao afirmar

[...] defendo que a experiência da disciplina "Mediação da Informação" do curso de Biblioteconomia UEL seja assumida, no âmbito da graduação em Biblioteconomia, nas outras escolas brasileiras da área. Quando adequado, a Mediação da Informação deve fazer parte dos cursos de pós-graduação em Ciência da Informação tanto lato, como stricto sensu. (ALMEIDA JỦNIOR, 2008, p. 52)

Assim, o entendimento e apropriação da mediação da informação enquanto ações que se desenvolvem em todos os setores de uma biblioteca universitária, bem como em todas as atividades do profissional bibliotecário tem se colocado como uma necessidade premente diante dos novos desafios surgidos na atualidade, em contextos cada vez mais ricos e variados, e sujeitos, cada vez mais diversos culturalmente em razão da ampliação das facilidades de acesso aos meios tecnológicos e ao ensino superior. 


\section{Considerações finais}

É perceptível o empenho de vários pesquisadores da área de ciência da informação e biblioteconomia em definir e avançar em estudos sobre mediação da informação, tanto implícita como explícita. Assim este estudo não deve estabelecer conclusões definitivas, mas contribuir em para enriquecimento do campo com novas discussões sobre esta temática.

Ressalta-se com esta revisão acerca dos conceitos de mediação da informação a multiplicidade de abordagens que podem ser aprofundadas de acordo com o objeto que se propõe. O olhar pode ser direcionado desde o empírico em sua essência mais imediata assim como pra abstrações teóricas e construção de conceitos que podem ser interessantes para a discussão epistemológica em Ciência da Informação.

Importante ressaltar que são necessárias ações prementes no intuito de realçar para a sociedade e para o próprio profissional bibliotecários as consequências de suas atividades para mudança social e desenvolvimento. Assim, percebemos a relevância de estudos com este escopo para desenvolvimento da área.

\section{Referências}

ALMEIDA JÚNIOR, Oswaldo Francisco de. Mediação da informação e múltiplas linguagens.

Tendências da Pesquisa Brasileira em Ciência da Informação, Brasília, v.2, n.1, p.89-103, jan./dez. 2009. Disponível em: <http:// inseer.ibict.br/ancib/index.php/tpbci/article/ viewFile/17/39>. Acesso em: 01 dez. 2017.

ALMEIDA JÚNIOR, Oswaldo Francisco de. Mediação da informação: ampliando o conceito de disseminação. In: VALENTIM, M. L. P. (Org.). Gestão da informação e do conhecimento. São Paulo: Polis; Cultura Acadêmica, 2008. p.41-54.

ALMEIDA JÚNIOR, Oswaldo Francisco de. Mediação da informação: um conceito atualizado. In: BORTOLIN, Sueli; SANTOS NETO, João Arlindo dos; SILVA, Rovilson José da (Org.). Mediação oral da informação e da leitura. Londrina: ABECIN, 2015. 278p. p.9-32.

ARAUJO, Carlos Alberto Ávila. O conceito de informação na Ciência da Informação. Inf. \& Soc.:Est., João Pessoa, v. 20, n. 3, p. 95-105, set./dez. 2010. Disponível em: < http://www.ies.ufpb.br/ojs/index.php/ies/article/view/6951/4808>. Acesso em: 18 out. 2017.

CAPURRO, Rafael. Epistemologia e ciência da informação. In: ENCONTRO NACIONAL DE PESQUISA EM CIÊNCIA DA INFORMAÇÃO, 5., 2003, Belo Horizonte. Anais... Belo Horizonte: Associação Nacional de Pesquisa e Pós-Graduação em Ciência da Informação e Biblioteconomia, 2003. Disponível em: < http://www.capurro.de/enancib_p.htm> Acesso em: 15 out. 2017

CAPURRO, Rafael; HJORLAND, Birger. O conceito de informação. Perspectivas em Ciência da Informação, Belo Horizonte, v. 12, n. 1, p. 148- 207, jan./abr. 2007. Disponível em: < 
http://portaldeperiodicos.eci.ufmg.br/index.php/pci/article/download/54/47> . Acesso em 20 out. 2017.

HUTCHINS, M. Introdução ao trabalho de referência em bibliotecas. Rio de Janeiro: Fundação Getulio Vargas, 1973. 294 p.

ORTEGA, Cristina Dotta. Da mediação em ciência da informação. Niterói, 2015. 122 f. Relatório final de pesquisa de pós-doutoramento (Programa de Pós-Graduação em Ciência da Informação - PPGCI) Universidade Federal Fluminense - UFF, Niterói, 2015.

SANCHES, Gisele A. Ribeiro; RIO, Sinomar Ferreira do. Mediação da informação no fazer do bibliotecário e seu processo em bibliotecas universitárias no âmbito das ações culturais. InCID: R. Ci. Inf. e Doc., Ribeirão Preto, v. 1, n. 2, p. 103-121, jul./dez. 2010. Disponível em: < http://www.revistas.usp.br/incid/article/download/42323/45994>. Acesso em: $01 \mathrm{dez} .2017$.

SANTOS NETO, João Arlindo dos; ALMEIDA JÚNIOR, Oswaldo Francisco de .O caráter implícito da mediação da informação. Inf. \& Soc.:Est., João Pessoa, v.27, n.2, p. 253-263, maio/ago. 2017. Disponível em: < https://www.google.com.br/url?sa=t\&rct=j\&q=\&esrc=s\&source=web\&cd=1\&ved=0ahUKEwjYn6HygIPYAhXPQd8KHUW8BkUQFggoMAA\&url=http\%3A\%2F\%2Fwww.ies.ufpb.br\%2Fojs\%2Findex.php $\% 2 F i e s \% 2 F a r t i c l e \% 2 F d o w n-$

load\%2F29249\%2Fpdf\&usg=AOvVaw1RqcRtJHK5xm2uem5_oWhX>. Acesso em: 05 dez. 2017.

SANTOS, Fabiana Pereira dos. O saber-fazer de bibliotecários de referência no desenvolvimento do letramento informacional acadêmico de graduandos. Belo Horizonte, 2015. 146f. Dissertação (Mestrado em Gestão Social, Educação e Desenvolvimento Local) Centro Universitário UNA, Belo Horizonte, 2015.

SILVA, Jonathas Luiz Carvalho. Percepções conceituais sobre mediação da informação. InCID: R. Ci. Inf. e Doc., Ribeirão Preto, v. 6, n. 1, p. 93-108, mar./ago. 2015. Disponível em: < http://www.revistas.usp.br/incid/article/download/89731/96288>. Acesso em: 05 dez. 2017. 